\title{
Is environmental efficiency trade inducing or trade hindering?
}

\author{
Seda Meyveci Doganay, Selin Sayek, Fatma Taskin * \\ Department of Economics, Bilkent University, Bilkent, Ankara 06800, Turkey
}

\section{A R T I C L E I N F O}

\section{Article history:}

Received 31 August 2013

Received in revised form 2 April 2014

Accepted 7 April 2014

Available online 18 April 2014

\section{JEL classification:}

F14

F18

Keywords:

Environmental efficiency index

Porter hypothesis

Gravity model

\begin{abstract}
A B S T R A C T
Global efforts to identify strategies for sustainable economic growth and development underline the need for understanding important links between environmental policies and international trade. In this paper, by constructing an environmental efficiency index for 111 countries from 1980 to 2009, we are able to empirically test for one such link. An improvement in the environmental efficiency index in terms of carbon dioxide emissions reflects a decrease in the cost of efforts to mitigate the environmental costs associated with growth. Countries that improve their environmental efficiency are found to experience strong international trade effects, both through increased exports and increased imports. While the positive link between efficiency improvements and exports is supportive of the Porter hypothesis, the positive link between efficiency improvements and imports is supportive of strong positive income effects on account of environmental efforts. These results, which are robust to alternative estimation strategies, lend strong support to global efforts to improve countries' environmental efficiencies.
\end{abstract}

(c) 2014 Elsevier B.V. All rights reserved.

\section{Introduction}

Over the past few decades, both through a significant reduction in tariff barriers and through increased international trade activities, a de jure and a de facto deepening of globalization, respectively, has been occurring. This trend has been accompanied by intensified competition pressures across countries to maintain a strong position in the game of globalization. It is believed that international trade is a main facilitator of much-needed (and much-sought) economic growth and employment generation for many countries (Frankel and Romer, 1999). However, in recent decades, a very relevant debate on sustainable growth and development versus sheer growth has added environmental, economic and sociopolitical sustainability to discussions around this belief. For example, appropriate technical changes in processes that improve the environmental efficiency of production would serve as a tool to achieve the goal of sustainability.

An important question is whether production schemes that become environmentally more efficient (or go green,) contribute to the competitiveness of the country and hence to its goal of maintaining a strong position in global trade activities. This debate is also relevant for international and national policymakers. The WTO, for example, emphasizes the legitimacy of setting environmental goals and going green, but also warns against making such environmental goals into non-tariff barriers and implicit (or even explicit) protectionist regulations, a phenomenon they call green protectionism. ${ }^{1}$ In 1994, in an effort to overcome the tension between legitimate environmental rules and green protectionism, the WTO established its Trade and Environment Committee. It also initiated several agreements that take into account these tensions, including the Sanitary and Phytosanitary Measures (SPS) Agreement and the Technical Barriers to Trade (TBT) Agreement.

Despite these globalized efforts, environmental standards do arise as an implicit non-tariff barrier that hinders international trade in many instances. As Esty (2001) notes, many of the issues tackled by the SPS and TBT agreements can indeed change international trade: "Public health standards, food safety requirements, emission limits, waste management and disposal rules, packaging and recycling regulations, and labeling policies all may shape trade flows." Many countries have complained to the WTO that their trading partners are unduly limiting their trade relationships because of environmental issues. According to Esty (2001), one such dispute was the tuna-dolphin case, in which the United States banned Mexican tuna imports in 1991 because the fishing methods resulted in incidental dolphin deaths. Another example is the European Union beef hormone dispute. The European Union has included "no added hormones in beef" as a food safety standard, and prefers this kind of beef in their imports. Yet another case is that of ongoing US sanctions against Thai shrimp, which they argue are caught using methods that kill endangered sea turtles. All such cases and disputes highlight the intertwined relationship between environmental

\footnotetext{
${ }^{1}$ For details one could look at the WTO Ministerial Declarations of 1994 and 2001, http://www.wto.org/english/tratop_e/envir_e/envir_req_e.htm.
}

\footnotetext{
* Corresponding author.

E-mail addresses: meyveci@bilkent.edu.tr (S.M. Doganay), sayek@bilkent.edu.tr (S. Sayek), taskin@bilkent.edu.tr (F. Taskin).
} 
concerns and international trade, pointing to the importance of providing further evidence on the direction of the relationship between these two very relevant variables.

The goal of this paper is to study how going green through improving the environmental efficiency of production plans is reflected in aggregate trade patterns. Environmental efficiency improvements would have important implications on countries' comparative advantage patterns, and therefore on international trade patterns.

The classic comparative advantage theory of international trade focuses on the relative costs of production as the main determinant of cross-country trade amounts. Some of the costs associated with production are environmental costs, which are influenced by changes in environmental awareness. Reductions in these environmental costs are equivalent to improvements in environmental efficiency. $^{2}$

In the following discussion, we map the link between environmental efficiency, costs and trade. If improvement in a country's efficiency decreases its cost structure, i.e. improves its comparative advantage, this cost advantage is expected to reflect itself in increased exports and decreased imports, according to classic trade theory. These effects could be thought of as a substitution effect, where at the aggregate level, countries switch from consuming high-cost goods to low-cost goods. Alongside this substitution effect, one could also envisage an indirect income effect, where this increased efficiency is expected to be associated with a country's increased income levels. Increased income is expected to contribute to increasing imports, rendering the overall sign of changes in imports uncertain. If the substitution effect outweighs the income effect, then the cost advantage (or efficiency improvement) is expected to decrease imports. If vice versa, then the cost advantage is expected to increase imports.

Hence, ex ante, we expect that environmental efficiency and exports move in the same direction, while the direction of change of imports depends on which of the substitution and income effects outweighs the other. When the substitution effect outweighs the income effect of efficiency changes, cost and imports move in the same direction, and inversely when reversed.

As such, in this paper, we examine the environment and international trade relationship by focusing on an environmental efficiency index, an output-based measure that reflects costs and has a clear link with international trade. ${ }^{3}$ A priori, if the substitution effect outweighs the income effect, we expect that improvements in a country's environmental efficiency would contribute positively to exports and negatively to imports. Taking this a priori expectation to data and testing for whether it holds for an extensive dataset is of empirical interest, and is the task we undertake in this paper.

This output-based environmental efficiency index used in the following analysis can best be summarized as an indicator reflecting the necessary cost to be incurred to improve the environmental quality of production, or in other words, reduce the environmentally unwanted outcomes of production. An improvement in the environmental efficiency index captures the idea that the cost of further eliminating one more unit of the "bad" will necessitate giving up fewer units of the "good," i.e. the environmental efficiency of production improves. The bad could include, but is not limited to, greenhouse gas emissions, water pollution, toxic waste discharge, overall negative impact on biodiversity and many other such negative externalities. These costs differ in where their effects are mostly felt; while some are confined locally, others generate a global impact. For the sake of generality and measurability, in this paper we will focus on those that create a global impact, mainly greenhouse gas emissions. According to a recent Environmental Protection Agency (EPA) report (2012), over 70\% of the greenhouse gas emitted is carbon dioxide $\left(\mathrm{CO}_{2}\right)$. Therefore, in the remainder of the paper, we associate and measure the environmental costs related to $\mathrm{CO}_{2}$ emissions.

We focus on the role played by environmental efficiency in influencing global trade patterns, and empirically test the link between environmental efficiency in $\mathrm{CO}_{2}$ emissions and international trade using an extensive dataset of 111 countries over the years 1980 to $2009 .{ }^{4}$ This extensive coverage contributes to the literature that has so far mainly focused on sub-sets of countries, due to the lack of consistent measurements regarding the environment. This study contributes to the literature by explicitly linking environmental efficiency, the main channel through which market pressures, environmental regulations and relevant technological changes play a role, with trade.

Prior studies linking international trade and environmental concerns have mostly focused on studying the role of environmental standards and regulations. This paper contributes to this literature by focusing on the role played by environmental efficiency. The literature identifies three drivers that lead to incorporating environmental concerns into production decisions: the financial returns of green production activities are expected to generate, environmental regulations and the cost reduction associated with these efforts (see Baines et al., 2012, who provide a detailed literature review on the evolution of green production). Limited evidence suggests that international environmental regulations contribute positively to countries' environmental efficiency, hence negatively to production costs (see Yörük and Zaim, 2006, 2008). Environmental regulatory stringency is expected to reflect itself as increased production costs, both for firms that opt to abide by the regulations as well as for those that choose not to. The former group will be forced to undertake costly restructuring activities. The latter group will face the risk of repercussions, bearing the implicit costs of trying to evade the regulations or the explicit costs if caught evading the regulations. Either way, environmental regulatory stringency is expected to increase costs incurred by firms. On the other hand, firms that do undertake the required costly technological restructuring are expected to benefit from improvements in their innovative state, which would be reflected as reductions in the cost of production. As such, there might be a close relationship between environmental efficiency and regulations, rendering the analysis of environmental efficiency and environmental regulations of important complementary areas. ${ }^{5}$

This topic of the effects of environmental standards/regulations on production schemes has been of significant interest in the literature for some time. While one strand of the literature argues that environmental standards would contribute positively to firm competitiveness by encouraging innovations and improving efficiency, ${ }^{6}$ another strand suggests an inverse association between environmental standards and competitiveness due to green protectionism. The latter argument suggests that environmental standards and regulations increase production costs, leading to a loss in competitiveness and lower international trade

\footnotetext{
2 The specific definition of environmental efficiency is provided in detail in the following discussion; at this stage, what is relevant is that an improvement in environmental efficiency is equivalent to reductions in environmental costs.

${ }^{3}$ Several studies use a similar measure of environmental efficiency, and they are reviewed in detail in the survey paper by Song et al. (2012). Even though earlier applications relied on firm-level data, the studies relevant to our analysis are those that use macro data for the Data Envelopment Analysis, which is necessary for the construction of these measures.
}

\footnotetext{
${ }^{4}$ Measuring the bad through $\mathrm{CO}_{2}$ emissions makes it possible to include 111 countries in the analysis. If instead of a single pollutant, for example, aggregate greenhouse emissions were examined, the dataset would only include 42 developed countries.

${ }^{5}$ The formal empirical testing of the link between environmental regulation and environmental efficiency is beyond the scope of this paper.

${ }^{6}$ Porter and van der Linde (1995) is one of the first studies on this issue, which were followed by several theoretical and empirical studies; which are surveyed in detail in the studies of Wagner (2003), Ambec and Barla (2006) and Ambec et al. (2013).
} 
figures. ${ }^{7}$ As such, according to the green protectionism hypothesis, one would expect an inverse relationship between exports and environmental standards. It is clear that the ultimate effect of regulation on international trade occurs through alterations of the comparative advantage patterns.

The empirical studies that fall into either of these two literature strands provide mixed evidence regarding the impact of environmental standards/regulation on trade flows, ${ }^{8}$ possibly on account of the difficulty in finding a universal measure of environmental regulation and standards, the divergences in the studies' country coverage and the choice of empirical methodology. The studies range from only OECD countries (Harris et al., 2002; Van Beers and Van Den Bergh, 1997, 2000), only members of the EU (De Santis, 2012; Jug and Mirza, 2005), a mixed sample of developed and developing countries (Cole and Elliott, 2003; Grether and de Melo, 2003; Tobey, 1990; Xu, 2000) and those focusing on the US or NAFTA (Ederington and Minier, 2003; Ederington et al., 2005; Levinson and Taylor, 2008). A wide range of studies is also evident in the choice of empirical methodology. Early studies analyzing the relationship between environment and trade used cross-sectional data (Cole and Elliott, 2003; Tobey, 1990; Van Beers and Van Den Bergh, 1997, 2000; Xu, 2000), whereas recent studies have moved toward using panel data (Ederington et al., 2005; Grether and de Melo, 2003; Harris et al., 2002; Jug and Mirza, 2005; Levinson and Taylor, 2008), taking into account the unobserved heterogeneity by correcting through fixed effects or alternative panel data estimations.

The studies also differ with respect to their theoretical framework. One group uses the Heckscher-Ohlin-Vanek (HOV) model of trade (e.g. Busse, 2004; Cole and Elliott, 2003; Tobey, 1990) and adds environmental stringency variables into the labor and capital endowments, whereas another group uses the gravity model of trade to construct the empirical equation to be estimated (Grether and De Melo, 2003; Harris et al., 2002; Jug and Mirza, 2005; Van Beers and Van den Bergh, 1997).

Finally, and more importantly, these studies use diverse measures of environmental stringency because there is no generally accepted indicator to account for international differences in environmental regulations. Studies use input oriented (Tobey, 1990; Van Beers and Van den Bergh, 2000) and output oriented measures (Van Beers and Van den Bergh, 1997). These measures can be based on surveys (Cole and Elliott, 2003; Tobey, 1990; Van Beers and Van den Bergh, 2000; Xu, 2000), energy consumption (Harris et al., 2002), environmental expenditure measured through total abatement-cost-based indicators (Ederington and Minier, 2003; Ederington et al., 2005; Jug and Mirza, 2005; Levinson and Taylor, 2008) or on regulatory gaps measured by the differences in GDP per capita (De Santis, 2012; Grether and de Melo, 2003).

On account of the variation in datasets, measurement and methodology, it is no surprise that the literature presents a range of conclusions about the relationship of trade and the environment. One group of studies finds no evidence that environmental standards affect pollutionintensive industries' trade flows (Tobey, 1990; Van Beers and Van den Bergh, 2000), nor the trade flows of environmentally sensitive goods (Xu, 2000) or aggregate exports (Harris et al., 2002). Several other studies find negative effects of more-stringent regulations on exports (Van Beers and Van den Bergh, 1997) and positive effects on exports

\footnotetext{
7 This inverse relationship between environmental regulations and trade is indeed the basis of both the green protectionism argument and the pollution haven hypothesis, which argues that on account of the expectation of this inverse relationship, countries get into a race-to-the-bottom competition of forgoing environmental standards to be able to compete in international trade (De Santis, 2012). While in this paper we make a reference to the aggregate trade balance effects of environmental standards; the pollution haven hypothesis more strongly suggests an alteration in the composition of traded goods in response to improved environmental standards. The compositional effects of these standards are a subject for future research, and we do not deal with them in this paper.

8 See also the literature review by Copeland and Taylor (2004).
}

(Van Beers and Van den Bergh, 2000) and imports (Ederington and Minier, 2003; Levinson and Taylor, 2008). ${ }^{9}$

As evident from above, even though the link between environmental stringency and trade relationship has been the topic of interest in many areas, especially in policy making, there is a lack of consensus around establishing a direct link between the stringency level of environmental regulations and its impact on international trade. This lack of consensus could be due to the difficulty of formulating certain links among going green in production, environmental regulation, cost and trade. By providing an explicit measure of environmental efficiency the following analysis contributes to formulating clear links among the above factors.

In this paper we take a cue from the recent literature by studying the link between environment and trade, and use the extended gravity model in formulating the empirical specifications. We start by estimating the gravity equation using pooled ordinary least squares (OLS) estimators, and then extend the analysis to include fixed effects. Following this baseline regression analysis, a series of robustness checks are conducted via use of the fixed-effect Poisson maximum likelihood estimation method, which overcomes both the inconsistencies resulting from heteroskedastic errors in log linear models as well as in the zero-trade problem and the instrumental variable estimation to avoid any possible simultaneity biases.

The findings of our analysis point to a strong and robust empirical relationship between environmental efficiency (in terms of $\mathrm{CO}_{2}$ emissions) and international trade. Improvements in the exporter country's environmental efficiency are positively associated with that country's exports, suggestive of supportive evidence for the Porter hypothesis and of the substitution effect due to the cost advantage generated from the improved environmental efficiency. Though a similar substitution effect is in operation for imports, our results suggest that the income effect on account of improved efficiency outweighs this substitution effect and induces increased imports as well as exports. These findings are robust to taking into account the problems of zero trade as well as possible endogeneities. The quantitative results allow a discussion of the trade effects of a multilateral effort, where the importing and the exporting countries both undertake environmental efficiency improvements. Such efforts are found to generate global positive welfare effects through increased global trade without generating additional current account imbalances. As such, the findings of this analysis are supportive of global multilateral efforts to implement environmental policies that would contribute to improvements in eco-friendly production schemes and internalize environmental efficiency concerns.

The study is laid out as follows: Section 2 discusses the data and the model, Section 3 provides a discussion of the results and Section 4 concludes.

\section{Model and data}

In studying the empirical association between environmental efficiency and international trade, the following analysis uses the gravity model. This model, used since 1962, when Tinbergen (1962) introduced it into the field of international economics, is based on Newton's universal law of gravitation. The theory states that bilateral trade flows are

\footnotetext{
9 Part of these differences can be accounted for by differences in the sectors included in the studies. Using the HOV model Busse (2004) concludes that there is no sufficient evidence to support the hypothesis that environmental stringency hinders trade; namely the pollution haven effect, except for iron and steel products. Similarly, Grether and de Melo (2003), running a gravity model, find support for the pollution haven hypothesis in the case of footloose sectors; however, their results are not robust to endogeneity. Jug and Mirza (2005), employing a gravity-type equation for EU countries by considering the endogeneity bias, find negative effects of environmental stringency on exports for dirty and clean sectors. Ederington et al. (2005) provide alternative explanations for the empirical failure of the pollution haven hypothesis. They point to the importance of the measure for footlooseness in determining the relationship between trade and environment, and state that stringency significantly affects net US imports from developing countries. Despite the value added in conducting the analysis across different sectors, due to data limitations, the analysis in this paper is conducted using aggregate data.
} 
positively related to the economic sizes of the two trading countries (measured by their respective GDPs) and negatively related to the distance between these countries:

Trade Flow $_{\mathrm{ij}}=\mathrm{aGDP}_{i} \cdot \mathrm{GDP} P_{j} / D_{\mathrm{ij}}$

where TradeFlow $i j$ is the bilateral trade flow from country $i$ to $j$, $G D P_{i}$ and $G D P_{j}$ are the gross domestic products of country $i$ and $j$, $D_{i j}$ is the distance between the two countries and $a$ is a gravitational constant depending on the units of measurement for mass and force.

Gravity models have now become standard methodology in empirically studying bilateral international trade patterns, especially given the increasing emphasis on its strong theoretical basis. ${ }^{10}$ The ample literature on international trade that uses the gravity model is surveyed in Anderson and van Wincoop (2004) and in Bergstrand and Egger (2011). More relevant for our purposes is the set of empirical papers that use the gravity model in studying the link between environment stringency and international trade, as is summarized in De Santis (2012). While many of these studies rely on the simple gravity framework, a significant share further extends the model to include variables such as population (or income per capita), adjacency, common language and colonial links, remoteness and border effects, among others, in the regression analysis. The following analysis is based on this type of extended version of the gravity model. In the next subsection we discuss the data used in the analysis, and provide the details in Appendix A.

\subsection{Data and measurement}

Bilateral trade flow data are obtained from the International Monetary Fund's (IMF) Direction of Trade Statistics. Income, population and land data are obtained from the World Banks' World Development Indicators (WDI), and variables, including the distance among countries, contiguity, common language and common colony are taken from the Centre d'Etudes Prospectives et d'Informations Internationales' (CEPII) Mayer and Zignago (2011) dataset.

The most important independent variable in the following analysis is the environmental efficiency index. In Appendix B we provide the technical details of the methodology of constructing the environmental efficiency index used in this paper, but it is also important to provide a summary of the index construction at this stage of the discussion.

\subsubsection{Environmental efficiency index}

According to standard neoclassical production theory, output produced using various inputs can be disposed of without incurring any cost, in terms of either reduced outputs or increased inputs. This situation is called strong disposability. However, pollutants created during production processes, which can be considered undesirable outputs, cannot be disposed of without incurring some cost. This situation is called weak disposability. Together, these factors create an asymmetry between the treatment of the output produced (desirable) and the environmental pollutants (undesirable) in terms of their disposability characteristics.

\footnotetext{
${ }^{10}$ Formal theoretical foundations of gravity models were first provided by Anderson (1979). Later, extensions to the basic model have been formulated by incorporating alternative market structures (Bergstrand, 1985, 1989; incorporates monopolistic competition), alternative preference structures (Deardorff, 1998; alternatively incorporates identical or constant elasticity substitution (CES) preferences), alternative trade frameworks (Eaton and Kortum; 2002, develop a Ricardian model of trade in homogenous goods) and more recently, micro foundations (Helpman et al., 2008; account for firm heterogeneity trade asymmetries and fixed trade costs, and develop a theory consistent with both zero and positive trade flows). Other studies have shown that the gravity model is consistent with incomplete specialization (Haveman and Hummels, 2004). Recent surveys include a literature review of the theoretical developments underpinning the gravity methodology (Anderson, 2011), as well as an econometric estimation and interpretation of these models in detail (Head and Mayer, 2013).
}

This distinction becomes especially meaningful when there is increased environmental consciousness that forces producing units to clean up the undesirable outputs created during production. Among many input-output combinations, producers are compelled to choose the production plan that maximizes desirable outputs while simultaneously minimizing resource use and pollution emissions. Hence, because of society's increased consciousness about the environment, undesirable outputs created in the production process become weakly disposable, i.e. some productive resources must be sacrificed to decrease the level of undesirable outputs. It is the amount of the desirable output sacrifice required in this transformation that determines the environmental efficiency of the production process.

One such measure of environmental efficiency is developed by Fare et al. (1989a,b), who use a hyperbolic graph efficiency index by comparing the production processes under alternative assumptions of undesirable output disposability. In Fare et al. (1989a,b), as well as in the following analysis, the environmental efficiency measure is derived from comparing two technical efficiency measures with respect to piecewise linear technologies that differ in terms of their assumption of undesirable output disposability. The environmental efficiency index quantifies the amount of desirable output loss due to the lack of strong disposability of undesirable outputs and measures the opportunity cost of transforming the production process from one where all outputs are strongly disposable (without any cost) to one that is characterized by weak disposability (by incurring cost) of undesirable outputs.

As opposed to methods that gauge environmental quality by pollutant emission levels, the indices derived in our study are based upon a production approach that differentiates between the disposability characteristics of environmentally desirable and undesirable outputs. Because regulation amendments, market pressures and pure technological advancements can change pollutants' disposability characteristics, this methodology offers an alternative, and possibly more precise measure of environmental costs by encompassing the change in the overall production process. Furthermore, the environmental efficiency index and the resulting cost measure are based on the amount of desirable output sacrificed to decrease the pollutant by 1 unit, which is a measure comparable across producers and over time. Hence, an improvement in the environmental efficiency index of producing a unit of output shows that the output cost of more-environmentally conscious producers diminishes and the cleanup costs are smaller, a situation that is likely to improve the producers' comparative advantage. ${ }^{11}$

The environmental efficiency index is computed using a nonparametric, non-stochastic production-frontier approach, where the position of each production unit (country) with respect to a world production frontier is constructed under alternative disposability assumptions for undesirable outputs. The ratio of these two efficiency scores provides the environmental efficiency index of a given year. Fare et al. (1989a), Zaim and Taskin (2000a,b) and Yörük and Zaim $(2006,2008)$ also use such non-parametric techniques and construct similar environmental efficiency indices. Given our focus on aggregate indicators, we follow the literature that uses macro data, and choose GDP as the desirable output, $\mathrm{CO}_{2}$ emissions as the weakly disposable undesirable output and compute an environmental efficiency index for each country for each year between 1980 and 2009, resulting in a dataset of 111 countries.

To calculate this environmental efficiency index, one needs data on aggregate output and environmental costs, as well as inputs used in the production of this aggregate output. We obtain the aggregate output measured by real GDP and the input indicators of labor and capital stock data from the Penn World Table 7.1, and obtain $\mathrm{CO}_{2}$ emissions

\footnotetext{
11 Indeed, this characteristic of the efficiency measurement renders an increase in its equivalent to a decrease in costs, and allows for the use of the two terms interchangeably; as is done throughout this paper.
} 
Table 1

Descriptive statistics.

\begin{tabular}{llllll}
\hline Variable & Obs. & Mean & Std. dev. & Min & Max \\
\hline Trade & 332,699 & $3,975,970$ & $3.96 \mathrm{E}+07$ & 0 & $3.10 \mathrm{E}+09$ \\
Income & 366,300 & $3.43 \mathrm{E}+08$ & $1.08 \mathrm{E}+09$ & $156,595.1$ & $1.31 \mathrm{E}+10$ \\
Distance & 366,300 & 7947.544 & 4394.933 & 10.47888 & $19,772.34$ \\
Environment eff. & 366,300 & $0.913227^{\mathrm{a}}$ & 0.1159974 & 0.4171762 & 1 \\
Population & 366,300 & $4.56 \mathrm{E}+07$ & $1.46 \mathrm{E}+08$ & 64,400 & $1.33 \mathrm{E}+09$ \\
Land & 363,990 & $875,951.7$ & $1,828,725$ & 300 & $9,327,430$ \\
\hline
\end{tabular}

Notes: Trade is measured as the total exports from country $i$ to country $j$ in current period USD, income is GDP of country $i$ in million USD, distance is the distance between country $i$ and $j$ in nautical miles. The environmental efficiency index is calculated by the authors, as detailed in Appendix B. Data for bilateral trade flows come from the IMF, data on distance come from the CEPII dataset, data for the calculation of the environmental efficiency index come from the Penn World Tables, and all remaining data are obtained from the WDI.

a We report the geometric mean of the environmental efficiency index.

(kilotons) from the WDI. ${ }^{12}$ The labor measure is imputed using the Purchasing Power Parity (PPP) Converted GDP Laspeyres per worker at 2005 constant prices, the PPP Converted GDP per capita Laspeyres at 2005 constant prices and population variables from the Penn World Tables. Capital stock is computed using the same dataset and implements the perpetual inventory method.

Table 1 provides the descriptive statistics of the final dataset, which is constructed to allow for an extensive coverage of developing and developed countries. ${ }^{13}$

\subsection{Model}

The estimation specification is as follows:

$$
\begin{aligned}
\ln X_{i j}= & \ln \beta_{1}+\beta_{1} \operatorname{lnGDP}_{i}+\beta_{2} \operatorname{lnGDP}_{j}+\beta_{3} \operatorname{lnDist}_{i j}+\beta_{4} \ln E F F_{i} \\
& +\beta_{5} \ln E F F_{j}+\beta_{6} \operatorname{lnPop}_{i}+\beta_{7} \operatorname{lnPop}_{j}+\beta_{8} \operatorname{lnLand}_{i}+\beta_{9} \operatorname{lnLand}_{j} \\
& +\beta_{10} \text { Contig }_{i j}+\beta_{11} \text { ComLang }_{i j}+\beta_{12} \text { ComCol }_{i j}+u_{i j},
\end{aligned}
$$

where $i$ denotes the exporting country and $j$ denotes the importing country, $X_{i j}$ measures the total exports of country $i$ to country $j$ in million US dollars (USD), GDP measures the respective country's GDP in million USD, Dist $t_{i j}$ measures the distance between country $i$ and $j$ in nautical miles, EFF is the environmental efficiency index in the respective country, Pop is the population, Land stands for land area, Contig $g_{i j}$ is a dummy that takes the value 1 if exporter $i$ and importer $j$ are contiguous, and zero otherwise, ComLang $i j$ is a dummy with value 1 if exporter $i$ and importer $j$ share a common language, and zero otherwise, and finally, $\mathrm{ComCol}_{i j}$ is a dummy with value 1 if both had a common colonizer after 1945 , and zero otherwise. ${ }^{14} u_{i j}$ is the log-normally distributed disturbance term.

\footnotetext{
12 WDI's account of $\mathrm{CO}_{2}$ emissions stems from the burning of fossil fuels and the manufacture of cement. These include $\mathrm{CO}_{2}$ produced during the consumption of solid, liquid and gas fuels; as well as gas flaring.

${ }^{13}$ The countries are Afghanistan, Islamic Republic of; Albania; Algeria; Angola; Argentina; Australia; Austria; Bangladesh; Barbados; Bolivia; Brazil; Bulgaria; Canada; Central African Republic; Chile; China, P.R.: Mainland; Colombia; Congo, Democratic Republic of; Congo, Republic of; Costa Rica; Côte d'Ivoire; Cyprus; Denmark; Dominican Republic; Ecuador; Egypt; El Salvador; Ethiopia; Fiji; Finland; France; Gabon; Gambia; Germany; Ghana; Greece; Guatemala; Haiti; Honduras; China P.R.: Hong Kong; Hungary; Iceland; India; Indonesia; Iran, Islamic Republic of; Iraq; Ireland; Israel; Italy; Jamaica; Japan; Jordan; Kenya; Korea, Republic of; Lebanon; Luxembourg; Madagascar; Malawi; Malaysia; Maldives; Mali; Malta; Mauritania; Mauritius; Mexico; Mongolia; Morocco; Mozambique; Nepal; Netherlands; New Zealand; Nicaragua; Niger; Nigeria; Norway; Pakistan; Panama; Papua New Guinea; Paraguay; Peru; Philippines; Poland; Portugal; Romania; Rwanda; Senegal; Seychelles; Sierra Leone; Singapore; South Africa; Spain; Sri Lanka; Sudan; Swaziland; Sweden; Switzerland; Syrian Arab Republic; Tanzania; Thailand; Togo; Trinidad and Tobago; Tunisia; Turkey; Uganda; United Kingdom; United States; Uruguay; Venezuela; Vietnam; Zambia; Zimbabwe. As such, the final dataset consists of 12,210 observations of bilateral export flows (111* 110 country pairs).

14 See Mayer and Zignago (2011) for further details.
}

Based on the gravity model, ex ante we expect to find the coefficient of the exporting and importing countries' income to be positive and that of the distance between the two countries' measure to be negative.

The premise of this analysis is that improvements in environmental efficiency would contribute to a country's competitiveness, à la Porter hypothesis, and hence lead to increased exports. Such a change in exports is expected on account of a change in the country's cost advantages, which leads to a substitution effect that induces increased exports from the country and decreased imports from the rest of the world. However, the effects of improvements in environmental efficiency are not limited to these relative cost changes. The country that undertakes such improvements is also expected to experience positive income changes, which would in turn induce secondary effects on imports. The overall effect on imports would depend on a comparison of the magnitude of this income effect with the substitution effect, as detailed above. The effect of a country's environmental efficiency index $\left(E F F_{i}\right)$ on a country's imports is tested through the coefficient of the importer country's environmental efficiency index variable in Eq. (1). The symmetry of the exports of country $i$ to country $j$ with the imports of country $j$ from country $i$ allows for studying the effects of a change in country $i$ 's $E F F_{i}$ on both its exports and its imports through the estimation of Eq. (1). While the sign of $\beta_{4}$ would capture the effects of a change in $E F F_{i}$ on $i$ 's exports, the sign of $\beta_{5}$ would capture its effects on $i$ 's imports (because it measures the effect of a change in $E F F_{i}$ on $j$ 's exports). ${ }^{15}$

The population variable is expected to represent the country's potential supply and demand for exports and imports, respectively. A country with a large population can more easily specialize in a wide range of commodities and, consequently, may be less dependent on foreign trade, which will lead to a negative coefficient. Alternatively, if the demand factors are dominant, the variable might result in a positive effect on exports.

Land variables are assumed to have a negative influence on trade. The larger a country's total area, the smaller the fraction of its economic activity that is expected to cross borders and the higher the probability of it becoming a relatively closed economy. Finally, we include three dummy variables, one on the circumstance of being a neighbor, one on sharing a common language and one on having been colonized by a common country. The coefficients of all three dummy variables are expected to be positive, as their existence should increase the level of bilateral trade.

Table 2 summarizes the expected signs of the coefficients in light of alternative theories.

\section{Empirical results}

We start by estimating Eq. (1) using the pooled OLS method, and report the results in column (1) of Table 3. As theoretically expected, the income of both trading partners as well as the distance between them has a positive and a negative sign, respectively, and is statistically significant. The coefficients of the population of both countries are found to be negative and significant. Land variables have insignificant coefficients with expected negative signs. All three factors capturing the contiguity of the two countries, as well as common cultural features such as a shared history or shared language, are found to positively and significantly explain bilateral export patterns.

The main question of interest in this analysis is to test the association between the bilateral trade and environmental efficiencies of the two trading partners. The environmental efficiency of the exporter country is found not to have a significant effect on the country's exports, whereas the importing country's environmental efficiency is found to

\footnotetext{
15 In our bilateral trade data; for the exports of country $i$ to country $j, X_{i j}$ is symmetrically defined as the imports of country $j$ from country $i$. Hence, for the exports of country $i$ to country $j$, the changes in $X_{i j}$ will be $\delta X_{i j} / \delta E f f i=\beta_{4}$; and for the imports of country $i$ from country $j$, the changes in $X_{j i}$ will be $\delta X_{j i} / \delta E f f_{i}=\beta_{5}$ when the efficiency of country $i$ improves by 1 unit.
} 
Table 2

Expected signs of coefficients.

\begin{tabular}{|c|c|c|}
\hline Variable & Expected sign & Interpretation \\
\hline Income of exporting country $i$ & + & Increased mass, à la gravity model. \\
\hline Income of importing country $j$ & + & Increased mass, à la gravity model. \\
\hline Distance between $i$ and $j$ & - & Increased cost-reducing trade, à la gravity model. \\
\hline Environmental efficiency index of exporting country $i$ & + & $\begin{array}{l}\text { Environmental efficiency improvements are synonymous with cost advantages, } \\
\text { which are expected to lead to comparative advantage changes that induce further exports. } \\
\text { This result is in line with the Porter hypothesis. }\end{array}$ \\
\hline \multirow[t]{4}{*}{ Environmental efficiency index of importing country $j$} & - & $\begin{array}{l}\text { Environmental efficiency improvements are synonymous with cost advantages, } \\
\text { which are expected to lead to comparative advantage changes that induce lower imports. } \\
\text { This substitution effect is expected to reflect itself in a negative sign of this coefficient. }\end{array}$ \\
\hline & + & Environmental efficiency improvements are expected to enrich a country. \\
\hline & & Increased income is expected to lead to increased demand for imports. \\
\hline & & Such an income effect is expected to reflect itself in a positive sign of this coefficient. \\
\hline Land of exporting country $i$ & - & $\begin{array}{l}\text { The larger a country's total area, the smaller the fraction of its economic activity that is expected to } \\
\text { cross borders and the higher probability of a relatively closed economy. }\end{array}$ \\
\hline Land of importing country $j$ & - & $\begin{array}{l}\text { The larger a country's total area, the smaller the fraction of its economic activity that is expected to } \\
\text { cross borders and the higher probability of a relatively closed economy. }\end{array}$ \\
\hline Population of exporting country $i$ & $+1-$ & $\begin{array}{l}\text { Population is a good approximation for the effects of economies of scale. A country with a large } \\
\text { population can more easily specialize in a wide range of commodities and, consequently, } \\
\text { may be less dependent on foreign trade, which may lead to a negative coefficient. } \\
\text { Alternatively, if the demand factors are dominant, the variable might result in a positive effect on exports. }\end{array}$ \\
\hline Population of importing country $j$ & $+1-$ & $\begin{array}{l}\text { Population is a good approximation for the effects of economies of scale. A country with a large population } \\
\text { can more easily specialize in a wide range of commodities and, consequently, } \\
\text { may be less dependent on foreign trade, which may lead to a negative coefficient. } \\
\text { Alternatively, if the demand factors are dominant, the variable might result in a positive effect on exports. }\end{array}$ \\
\hline Common language & + & Its existence will increase the level of bilateral trade. \\
\hline Contiguity & + & Its existence will increase the level of bilateral trade. \\
\hline Common colonization & + & Its existence will increase the level of bilateral trade. \\
\hline
\end{tabular}

Notes: The ex ante expectations of the sign of the coefficients are based on the detailed literature survey conducted by the authors.

play a positive role in bilateral exports from its exporting partners. ${ }^{16}$ The results so far ignore the very valuable panel nature of the dataset; we take this nature into account in column (2). Doing so not only enables us to deal with the heterogeneity bias that exists in estimating the gravity equation with OLS, but also enables us to consider the trade costs/resistances that Anderson and van Wincoop (2003) suggest to be included in gravity equations. Following the literature, given the difficulty of obtaining the relevant price indices that would allow calculating such trade resistances, we include country-pair fixed effects. This inclusion is a standard procedure in the literature; Feenstra (2004) and Baldwin and Taglioni (2006) have shown that including such fixed effects provides similar results to those of Anderson and van Wincoop (2003). While all results remain the same, in controlling for such fixed effects, which possibly include trade resistances alongside many country- and pair-specific factors, the exporter country's environmental efficiency becomes an influential factor in the country's export performance, alongside the importer's environmental efficiency. In short, these results show that improvements in a country's environmental efficiency positively contribute to that country's exports as well as its imports.

The former of these results suggests that a country's improved environmental efficiency generates cost advantages that contribute to the country's competitiveness, leading to increased exports. In other words, the positive sign of the coefficient of the exporter's environmental efficiency gives supporting evidence for the Porter hypothesis. In interpreting the coefficient of the importer's environmental efficiency index, we make use of the fact that country $i$ 's exports to country $j$ are equivalent to country $j$ 's imports from country $i$. Hence, an improvement in country $j$ 's environmental efficiency affects the exports of country $i$ to $j$, or the imports of country $j$ from $i$. The positive coefficient of the importer's efficiency index, $E F F_{j}$, therefore suggests that a country's environmental efficiency improvements increase its imports from trading partners. The positive association between a country's environmental efficiency and imports suggests that the

\footnotetext{
16 The Variance Inflation Factor (VIF) scores, which test multicolinearity, are lower than 10 (with an average of 2.06) supporting that there is no multicolinearity problem.
}

income effect on account of these efficiency improvements outweighs the substitution effect.

Recently, the estimation techniques of gravity models have been criticized for inconsistent estimates, the result of log-linearization of the empirical model in the presence of heteroskedasticity (see Silva and Tenreyro (2006)). It is shown that in the presence of heteroskedasticity, standard methods can severely bias the estimated coefficients. To overcome this problem, Silva and Tenreyro (2006) propose a simple Poisson pseudo-maximum-likelihood method (PPML). The PPML method provides not only a robust solution to different patterns of heteroskedasticity but also a natural way to deal with the zeros that prevail in the trade data. As such, in the last two columns of Table 3, we report the results of the fixed-effects Poisson estimation, without and with time effects, respectively.

The extent of zero-trade problems is evident in the $36 \%$ additional observations included in the Poisson estimation compared to the OLS regressions. The interpretation of all variables remains unchanged from the previous analysis.

It is possible that international trade flows and GDP as well as environmental efficiency and international trade flows are riddled with reverse causality, rendering the OLS coefficients inconsistent. Indeed, studies such as those by Ederington and Minier (2003), Levinson and Taylor (2008) and Zaim and Taskin (2000a), among others, point to the potential existence of such endogeneity biases. ${ }^{17}$ To control for such problems, in columns (1) and (4) of Table 4, we use the instrumental variable OLS and the generalized method of moments (GMM) estimator with paired fixed effects, respectively, in estimating the gravity equation. We select lagged GDP variables and lagged environmental efficiency indices as possible instruments, according to Hansen's Jstatistics. The first-stage regression F-statistics are quite high, signaling that the instruments are highly correlated with the independent variable GDP and environmental efficiency, and that they support the validity of instrument choices. The main results of the analysis also

\footnotetext{
17 The endogeneity tests, reported at the end of Table 4, strongly reject the hypothesis that the income and environmental efficiency indices for the exporting and importing countries can actually be treated as exogenous.
} 
Table 3

Estimation results. Dependent variable: exports of country $i$ to country $j, 1980-2009$.

\begin{tabular}{|c|c|c|c|c|c|}
\hline \multirow[t]{3}{*}{ Variables } & \multirow{2}{*}{$\begin{array}{l}(1) \\
\text { Pooled }\end{array}$} & \multirow{2}{*}{$\begin{array}{l}(2) \\
\text { Fixed }_{i j}\end{array}$} & \multirow{2}{*}{$\frac{(3)}{\text { Fixed }_{i j, t}}$} & \multirow{2}{*}{$\begin{array}{l}\frac{(4)}{\mathrm{PQML}_{i j}} \\
\end{array}$} & \multirow{2}{*}{$\frac{(5)}{\mathrm{PQML}_{i j, t}}$} \\
\hline & & & & & \\
\hline & $\ln X_{i j}$ & $\ln X_{i j}$ & $\ln X_{i j}$ & $X_{i j}$ & $X_{i j}$ \\
\hline $\ln G D P_{i}$ & $\begin{array}{l}1.462^{* * * *} \\
(0.016)\end{array}$ & $\begin{array}{l}1.604^{* * *} \\
(0.043)\end{array}$ & $\begin{array}{l}1.660^{* * * *} \\
(0.049)\end{array}$ & $\begin{array}{l}1.355^{* * * *} \\
(0.103)\end{array}$ & $\begin{array}{l}1.234^{* * * *} \\
(0.112)\end{array}$ \\
\hline $\ln G D P_{j}$ & $\begin{array}{l}1.039^{* * *} \\
(0.015)\end{array}$ & $\begin{array}{l}1.098^{* * *} \\
(0.041)\end{array}$ & $\begin{array}{l}1.136^{* * *} \\
(0.046)\end{array}$ & $\begin{array}{l}1.177^{* * *} \\
(0.107)\end{array}$ & $\begin{array}{l}1.028^{* * * *} \\
(0.105)\end{array}$ \\
\hline lnDist $_{i j}$ & $\begin{array}{l}-1.105^{* * * *} \\
(0.024)\end{array}$ & (Omitted) & (Omitted) & (Omitted) & (Omitted) \\
\hline $\ln E F F_{i}$ & $\begin{array}{l}0.015 \\
(0.160)\end{array}$ & $\begin{array}{l}0.547^{* * *} \\
(0.106)\end{array}$ & $\begin{array}{l}0.374^{* * * *} \\
(0.112)\end{array}$ & $\begin{array}{l}0.582^{* * *} \\
(0.212)\end{array}$ & $\begin{array}{l}0.601^{* * *} \\
(0.214)\end{array}$ \\
\hline $\ln E F F_{J}$ & $\begin{array}{l}0.361^{* * *} \\
(0.133)\end{array}$ & $\begin{array}{l}0.445^{\text {**** }} \\
(0.087)\end{array}$ & $\begin{array}{l}0.295^{* * *} \\
(0.092)\end{array}$ & $\begin{array}{l}0.937^{* * * *} \\
(0.202)\end{array}$ & $\begin{array}{l}0.953^{* * *} \\
(0.196)\end{array}$ \\
\hline $\operatorname{lnLand}_{i}$ & $\begin{array}{l}-0.000 \\
(0.014)\end{array}$ & (Omitted) & (Omitted) & (Omitted) & (Omitted) \\
\hline $\operatorname{lnLand}_{j}$ & $\begin{array}{l}-0.099^{* * *} \\
(0.013)\end{array}$ & (Omitted) & (Omitted) & (Omitted) & (Omitted) \\
\hline $\operatorname{lnPop}_{i}$ & $-0.331^{* * * *}$ & $-\overline{1.271^{* * *}}$ & $-1.004^{* * *}$ & -0.565 & $-0.662^{*}$ \\
\hline & $(0.020)$ & $(0.097)$ & $(0.102)$ & $(0.357)$ & $(0.342)$ \\
\hline $\operatorname{lnPop}_{j}$ & $-0.078^{* * *}$ & - & $-0.214^{* *}$ & - & - \\
\hline & $(0.021)$ & $\begin{array}{l}0.505^{* * *} \\
(0.084)\end{array}$ & $(0.094)$ & $\begin{array}{l}1.022^{* * *} \\
(0.255)\end{array}$ & $\begin{array}{l}1.080^{* * * *} \\
(0.224)\end{array}$ \\
\hline Contig $_{i j}$ & $\begin{array}{l}0.930^{* * *} \\
(0.130)\end{array}$ & (Omitted) & (Omitted) & (Omitted) & (Omitted) \\
\hline ComLang $_{i j}$ & $\begin{array}{l}0.755^{* * *} \\
(0.053)\end{array}$ & (Omitted) & (Omitted) & (Omitted) & (Omitted) \\
\hline ComCol $_{i j}$ & $\begin{array}{l}0.944^{* * *} \\
(0.113)\end{array}$ & (Omitted) & (Omitted) & (Omitted) & (Omitted) \\
\hline Constant & - & - & - & & \\
\hline & $\begin{array}{l}17.476^{* * *} \\
(0.348)\end{array}$ & $\begin{array}{l}9.186^{* * *} \\
(1.288)\end{array}$ & $\begin{array}{l}19.678^{* * *} \\
(2.304)\end{array}$ & & \\
\hline Observations & 234,921 & 234,921 & 234,921 & 318,591 & 318,591 \\
\hline R-squared & 0.627 & 0.178 & 0.182 & & \\
\hline $\begin{array}{l}\text { Number of cross- } \\
\text { sec }\end{array}$ & & 11,171 & 11,171 & 11,171 & 11,171 \\
\hline Paired effect & No & Yes & Yes & Yes & Yes \\
\hline Time effect & No & No & Yes & No & Yes \\
\hline
\end{tabular}

Notes: Robust standard errors are reported in parentheses. ${ }^{* * *}$ denotes $\mathrm{p}<0.01,{ }^{* *}$ denotes $\mathrm{p}<0.05$, and ${ }^{*}$ denotes $\mathrm{p}<0.1$. Trade is the bilateral exports from country $i$ to country $j$. $G D P_{i}$ and $G D P_{j}$ are the gross domestic product of country $i$ and $j$, respectively. Dist $t_{i j}$ is the distance between country $i$ and $j . E F F_{i}$ and $E F F_{j}$ are the environmental efficiency indices of country $i$ and $j$, respectively. $P o p_{i}$ and $P p_{j}$ are the population of country $i$ and $j$, respectively. Land $_{i}$ and $L a n d_{j}$ are the land area of country $i$ and $j$, respectively. Contig $g_{i j}$ is a dummy that takes 1 if both exporter $i$ and importer $j$ are contiguous, and zero otherwise. ComLang ij $_{\text {ij }}$ a dummy with value 1 if both exporter $i$ and importer $j$ share a common language, and zero otherwise. Comcol $_{i j}$ is a dummy with value 1 if both had a common colonizer after 1945, and zero otherwise. All variables that start with "l" denote the logarithmic transformation of the variable.

prevail when overcoming the endogeneity biases, where a country's exports are positively associated with the country's own environmental efficiency as well as with the importer country's environmental efficiency.

Overall, regardless of the estimation technique, the environmental efficiencies of the exporter and the importer countries are shown to contribute positively to the extent of bilateral trade between these two countries. In other words, all these regression results point to a very robust positive relationship among a country's environmental efficiency, its exports and its imports. The robustly positive sign of $E F F_{i}$ provides strong support for the Porter hypothesis, while the robustly positive sign of $E F F_{j}$ provides evidence for income effects that are stronger than substitution effects, due to environmental efficiency improvements.

The total trade impact of a hypothetical scenario of increased environmental awareness in all partner countries can be quantified with the results of these estimations. For example, in a case when two trade partners adopt similar standards regarding environmental pollution (or $\mathrm{CO}_{2}$ emissions) and experience similar improvements in their environmental efficiency scores, their exports and imports will increase.
In the following discussion, we use the regression results reported in column (4) of Table 4, which take into account the possible endogeneities. Specifically, take the case in our setting where both the exporter $\left(E F F_{i}\right)$ and the importer country's environmental efficiency index $\left(E F F_{j}\right)$ change symmetrically with equal percentage changes: given the positive sign of both countries' environmental efficiency index an equal increase in both indices will suggest an increase in total trade (exports plus imports). The coefficients suggest that a $1 \%$ improvement in the environmental efficiency of countries $i$ and $j$ would lead to an increase in the exports of country $i$ by $(0.591 \%+$ $0.310 \%=0.901 \%)$ and, symmetrically, the exports of country $j$ by $(0.591 \%+0.310 \%=0.901 \%)$. That is, total world trade increases by $1.802 \%$ on account of a symmetric $1 \%$ improvement in the environmental efficiency of both countries. The increase of country $i$ 's exports is equivalent to the increase in country $j$ 's imports, and vice versa. As such, the imports and exports of each country increase by the same magnitude, suggesting no change in the current account balances as a result of these environmental efficiency changes.

The positive and significant coefficients of the exporter's and the importer's environmental efficiency in creating trade is evidence that joint efforts in environmental efficiency improvements lead to increased global trade activities. It is, however, more relevant that because these improvements are symmetric qualitatively and quantitatively they do not impact the current account balances of either country. As such, without any current account imbalance cost, multilateral environmental efficiency improvements due to increased environmental awareness are found to create a more-efficient allocation of global resources, both in decreasing the negative externality of production and in better resource allocation, according to the welfare results of the classic trade theory as reflected in increased global trade.

\section{Conclusion}

The global efforts of identifying strategies for sustainable economic growth and development underline the need for understanding the important links between environmental concerns and international trade. This paper contributes to this debate by empirically studying the link between environmental efficiency improvements in terms of $\mathrm{CO}_{2}$ emissions and international trade patterns, using an extensive dataset that covers 111 countries over almost three decades. This alternative measure of environmental performance, constructed for such a wide range of countries and an extensive time period, is in itself of significance and allows studying the environment and international trade in an encompassing manner.

Making use of the gravity equation framework, we are able to robustly show that improvements in a country's environmental efficiency positively contribute to the country's international linkages through increased exports and increased imports. The positive link between environmental efficiency and exports lends strong support to the Porter hypothesis, suggesting a competitiveness improvement upon environmentally more-efficient production. This result can also be interpreted as being suggestive of a substitution effect (on account of an improvement of the relative cost advantages of countries due to environmental efficiency changes); the resulting cost advantages are found to create exports while limiting imports. However, the positive link between environmental efficiency and imports suggests that the substitution effect leading to less imports is outweighed by a stronger income effect, where this income effect is on account of the improvements in a country's environmental efficiency, which in turn contributes to increased demand for imports.

The findings of this analysis also provide strong support for global multilateral environmental efforts, where countries' joint environmental efficiency improvements are found to contribute positively to world welfare through increased global trade activities and without creating any distributional effects through current account imbalances. This finding is of great value in a policy environment where joint efforts 
Table 4

Endogeneity problem. Dependent variable: exports of country $i$ to country $j, 1980-2009$.

\begin{tabular}{|c|c|c|c|c|}
\hline \multirow[t]{4}{*}{ Variables } & $(1)$ & $(2)$ & (3) & (4) \\
\hline & \multirow{2}{*}{$\begin{array}{l}\text { IV-OLS } \\
\text { Fixed }_{i j}\end{array}$} & \multirow{2}{*}{$\begin{array}{l}\text { IV-OLS } \\
\text { Fixed }_{i j, t}\end{array}$} & \multirow{2}{*}{$\begin{array}{l}\text { IV-GMM } \\
\text { Fixed }_{i j}\end{array}$} & \multirow{2}{*}{$\begin{array}{l}\text { IV-GMM } \\
\text { Fixed }_{i j, t}\end{array}$} \\
\hline & & & & \\
\hline & $\ln X_{i j}$ & $\ln X_{i j}$ & $\ln X_{i j}$ & $\ln X_{i j}$ \\
\hline \multirow[t]{2}{*}{$\ln G D P_{i}$} & $1.681^{* * *}$ & $1.769^{* * *}$ & $1.681^{* * *}$ & $1.768^{* * *}$ \\
\hline & $(0.048)$ & $(0.056)$ & $(0.048)$ & $(0.056)$ \\
\hline \multirow[t]{2}{*}{$\ln G D P_{j}$} & $1.034^{* * * *}$ & $1.109^{* * *}$ & $1.033^{* * *}$ & $1.109^{* * * *}$ \\
\hline & $(0.046)$ & $(0.053)$ & $(0.046)$ & $(0.053)$ \\
\hline $\operatorname{lnDist}_{i j}$ & (Omitted) & (Omitted) & (Omitted) & (Omitted) \\
\hline \multirow[t]{2}{*}{$\ln E F F_{i}$} & $0.772^{* * * *}$ & $0.590^{* * * *}$ & $0.767^{* * *}$ & $0.591^{* * *}$ \\
\hline & $(0.136)$ & $(0.140)$ & $(0.136)$ & $(0.140)$ \\
\hline \multirow[t]{2}{*}{$\ln E F F_{j}$} & $0.436^{* * *}$ & $0.287^{* *}$ & $0.372^{* * *}$ & $0.310^{* * *}$ \\
\hline & $(0.114)$ & $(0.118)$ & $(0.105)$ & $(0.109)$ \\
\hline $\operatorname{lnLand}_{i}$ & (Omitted) & (Omitted) & (Omitted) & (Omitted) \\
\hline $\operatorname{lnLand}_{j}$ & (Omitted) & (Omitted) & (Omitted) & (Omitted) \\
\hline \multirow[t]{2}{*}{$\ln P_{0} p_{i}$} & $-1.303^{* * * *}$ & $-1.072^{* * *}$ & $-1.304^{* * *}$ & $-1.072^{* * *}$ \\
\hline & $(0.109)$ & $(0.113)$ & $(0.109)$ & $(0.113)$ \\
\hline \multirow[t]{2}{*}{$\ln P o p_{j}$} & $-0.332^{* * *}$ & -0.091 & $-0.322^{* * *}$ & -0.096 \\
\hline & $(0.093)$ & $(0.102)$ & $(0.093)$ & $(0.101)$ \\
\hline Contig $_{i j}$ & (Omitted) & (Omitted) & (Omitted) & (Omitted) \\
\hline ComLang $_{i j}$ & (Omitted) & (Omitted) & (Omitted) & (Omitted) \\
\hline $\mathrm{ComCol}_{i j}$ & (Omitted) & (Omitted) & (Omitted) & (Omitted) \\
\hline Observations & 222,506 & 222,506 & 222,506 & 222,506 \\
\hline R-squared & 0.177 & 0.180 & 0.178 & 0.180 \\
\hline Number of cross-sec & 10,829 & 10,829 & 10,829 & 10,829 \\
\hline Hansen J-test & 2.146 & 0.273 & 2.146 & 0.273 \\
\hline p-Value & 0.1429 & 0.6013 & 0.1429 & 0.6013 \\
\hline Endogeneity test & 119.614 & 117.850 & 119.614 & 117.850 \\
\hline p-Value & 0.0000 & 0.0000 & 0.0000 & 0.0000 \\
\hline $\begin{array}{l}\text { Wald } \chi^{2} \text { test }\left(\mathrm{H}_{0} \text { : }\right. \\
\left.\quad \text { leff }_{j} \geq \text { leff }_{i}\right)\end{array}$ & 3.46 & 2.83 & 5.05 & 2.57 \\
\hline p-Value & 0.031 & 0.046 & 0.012 & 0.054 \\
\hline Paired effect & Yes & Yes & Yes & Yes \\
\hline Time effect & No & Yes & No & Yes \\
\hline
\end{tabular}

Notes: Robust standard errors are reported in parentheses. ${ }^{* * *}$ denotes $\mathrm{p}<0.01,{ }^{* *}$ denotes $\mathrm{p}<0.05$, and ${ }^{*}$ denotes $\mathrm{p}<0.1$. Trade is the bilateral exports from country $i$ to country $j$. $G D P_{i}$ and $G D P_{j}$ are the gross domestic product of country $i$ and $j$, respectively. Dist $t_{i j}$ is the distance between country $i$ and $j . E F F_{i}$ and $E F F_{j}$ are the environmental efficiency indices of country $i$ and $j$, respectively. Pop $p_{i}$ and $P_{0} p_{j}$ are the population of country $i$ and $j$, respectively. Land $_{i}$ and $L a n d_{j}$ are the land area of country $i$ and $j$, respectively. Contig ij a dummy that takes 1 if both exporter $i$ and importer $j$ are contiguous, and zero otherwise. ComLang $i j$ is a dummy with value 1 if both exporter $i$ and importer $j$ share a common language, and zero otherwise. Comcol $_{i j}$ is a dummy with value 1 if both had a common colonizer after 1945, and zero otherwise. All variables that start with "l" denote the logarithmic transformation of the variable.

such as the Kyoto Protocol take significant time and convincing across countries.

This study provides strong evidence supporting countries' environmental efficiency improvement efforts, and future research should shed light on whether any country-specific factors affect the link between such efforts and international trade. Future research should consider conditions under which the effects of environmental efficiency on international trade differ across countries. Other research could examine what kinds of industries' and goods' international trade patterns are affected by environmental efficiency improvements. Such a study would allow further disentangling of the pollution haven hypothesis, and would build on the findings of the current paper, which finds robust evidence for the Porter hypothesis. Linking environmental efficiency with environmental regulation is another important strand of future work that would contribute to our understanding of the environment and trade.

\section{Acknowledgments}

We are grateful to Banu Demir Pakel for her helpful comments and to the participants of the macro study group in the Bilkent University Economics Department. The views expressed in this paper are those of the authors.

\section{Appendix A. Data description and sources}

Bilateral exports from country $i$ to country $j\left(X_{i j}\right)$

Measures the total exports from country $i$ to country $j$ in current period USD. The variable is converted into real terms by export price indices. Source: Direction of Trade Statistics, IMF.

Gross domestic product of country $i$ and $j\left(G D P_{i}\right.$ and $\left.G D P_{j}\right)$

GDP at purchaser's prices in million USD. Data are in constant 2005 USD. Source: World Development Indicators, World Bank.

Distance between country $i$ and $j$ (Dist ${ }_{i j}$ )

The simple distances calculated following the great circle formula, which uses the latitude and longitude of a country's most important city (in terms of population) or of its official capital in nautical miles. Source: CEPII Mayer and Zignago (2011) dataset.

Population of country $i$ and $j\left(\right.$ Pop $_{i}$ and $\left.\mathrm{Pop}_{j}\right)$

Total population is based on the de facto definition of population, which counts all residents regardless of legal status or citizenshipexcept for refugees not permanently settled in the country of asylum, who are generally considered part of the population of their country of origin. The values shown are midyear estimates. Source: World Development Indicators, World Bank.

\section{Land area of country $i$ and $j\left(\right.$ Land $_{i}$ and Land $\left._{j}\right)$}

Land area is a country's total area, excluding area under inland water bodies, national claims to a continental shelf and exclusive economic zones. In most cases, the definition of inland water bodies includes major rivers and lakes. Source: World Development Indicators, World Bank.

\section{Common language (ComLang $i j$ )}

A dummy variable indicating whether the two countries share a common official language. Source: CEPII Mayer and Zignago (2011) dataset.

\section{Common colonizer ( $\left.\mathrm{ComCol}_{i j}\right)$}

A dummy variable indicating whether the two countries had a common colonizer after 1945. Source: CEPII Mayer and Zignago (2011) dataset.

\section{Contiguity (Contig ${ }_{i j}$ )}

Dummy variable indicating whether the two countries are contiguous. Source: CEPII Mayer and Zignago (2011) dataset.

\section{Environmental efficiency index $\left(E F F_{i}\right.$ and $\left.E F F_{j}\right)$}

The necessary output loss to get rid of a unit of environmentally unwanted effects of production. Source: Calculated by the authors, using data from the World Bank and the Penn World Tables. 


\section{Appendix B. The computation of environmental efficiency indices}

The environmental efficiency index is obtained by comparing two technologies that differ with respect to their disposability assumption of undesirable output. Shephard's (1970) production model explicitly includes the production of undesirable output, which can be reduced with a proportional decrease in desirable output, i.e. it is weakly disposable. Fare et al. (1989a,b) utilize a hyperbolic efficiency measure to construct an environmental efficiency index using a non-parametric piece-wise linear technology that can be depicted by the following figure:

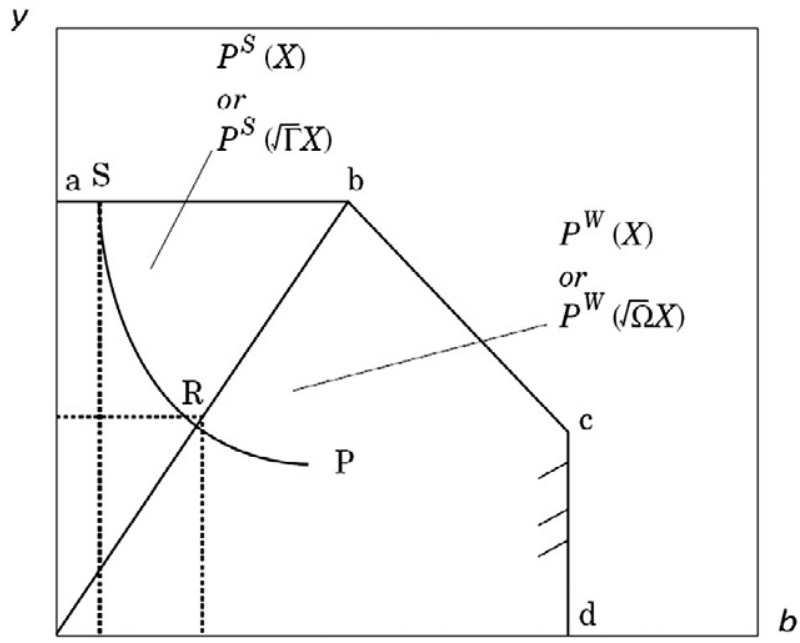

Fig. 1. Output sets for strongly and weakly disposable undesirable outputs.

Good output ( $y$ ) and bad output ( $b$ ) are produced using inputs. The production set depicted by the line segments $O a, a b, b c$ and $c d$ represents the strongly disposable bad output, whereas $\mathrm{Ob}, b c$ and $c d$ represent the weakly disposable production set. In the former case, a movement along the $O a$ segment decreases bad output $B$ with no sacrifice of good output for a given amount of inputs, hence illustrates the strong disposability assumption. In the latter case, that of weak disposability, it is possible along $O b$ to decrease bad output levels only if some resources are transferred from the production of good output to the cleanup of the bad, hence with a sacrifice of good output.

The hyperbolic measure of technical efficiency denotes the largest proportionate expansion in good output while contracting the inputs and the bad output. Comparing the hyperbolic technical efficiency indices with respect to both production frontiers yields a measure of environmental efficiency, which is interpreted as the good output sacrifice necessary in order to decrease the bad output by 1 unit, due to the forced weak disposability of pollutants by the imposition of environmental regulations.

Formally, the production structure is such that there are $K$ producers, which use inputs $x \in R_{+}^{N}$ to produce good outputs $y \in R_{+}^{M}$ and bad outputs $b \in R_{+}^{J}$ (pollutants). The data matrices are $M$, a $K \times M$ matrix of good output, with ki'th element, $y_{i k}$ is the amount of good output $i$ produced by the k'th producer; $J$, a $K \times J$ matrix of bad output, with $k i$ 'th element and $b_{i k}$ the amount of bad output $i$ produced by the $k$ 'th producer and finally $N$, a $K \times N$ matrix of inputs, with ki'th element and $x_{i k}$ the amount input $i$ used by the $k$ 'th producer. $N, J$ and $M$ are non-negative matrices having strictly positive row sums and column sums.

The production set that satisfies strong disposability of both outputs can be depicted in terms of the data matrices as:

$P^{s}(x)=\left\{(y, b): z^{T} M \geq y, z^{T} J \geq b, z^{T} N \leq x, z \in R_{+}^{K}\right\}$, where $z$ is a $K \times 1$ vector of intensity variables. The production set with strong disposability of good output and weak disposability of bad output is shown as:

$P^{w}(x)=\left\{(y, b): z^{T} M \geq y, z^{T} J=b, z^{T} N \leq x, z \in R_{+}^{K}\right\}$.

The hyperbolic technical efficiency index with respect to any production set is computed as the maximum simultaneous proportionate expansion of the good output and the contraction of the inputs and bad output, subject to the constraint of the technology. The environmental efficiency index defined by Fare et al. (1989a,b) is obtained by comparing technical efficiency indices with respect to two technologies, with a differing disposability characteristic for the bad output.

For a constant returns to scale (CRS) technology that satisfies the strong disposability of inputs and outputs, a hyperbolic graph of the technical efficiency measure is defined for producer $k, k=1, \ldots, K$ as: $H_{0}^{S}\left(y^{k}, b^{k}, x^{k}\right)=\min \left\{\lambda:\left(\lambda x^{k}, \lambda^{-1} y^{k}, \lambda b^{k}\right) \in P^{S}(x)\right\}$.

$H_{0}^{S}$ maximizes $\lambda$ hyperbolically to expand the data point $\left(y^{k}, b^{k}, x^{k}\right)$ to the frontier of the production set $\left(\lambda x^{k}, \lambda^{-1} y^{k}, \lambda b^{k}\right)$.

Each production unit $k$ can be computed as the solution to the following programming problem:

$$
\begin{aligned}
& H_{0}^{S}\left(y^{k}, b^{k}, x^{k}\right)=\min \lambda \\
& \text { s.to } \\
& z^{T} Y \geq \lambda^{-1} y^{k} \\
& z^{T} B \geq \lambda b^{k} \\
& z^{T} N \leq \lambda x^{k} \\
& z^{T} \in R_{+}^{K}
\end{aligned}
$$

For computational purposes, the non-linear programming problems in LP1 can be converted into a linear programming problem, as in LP2, where $\Gamma=\lambda^{2}$ and $Z=\lambda z$. Then the solution is derived by solving $\sqrt{\Gamma}$.

$$
\begin{aligned}
& H_{0}^{S}\left(y^{k}, b^{k}, x^{k}\right)=\min \lambda \\
& \text { s.to } \\
& Z^{T} Y \geq y^{k} \\
& Z^{T} B=\Gamma b^{k} \\
& Z^{T} N \leq \Gamma x^{k} \\
& Z^{T} \in R_{+}^{K} .
\end{aligned}
$$

For a CRS technology that satisfies weak disposability for the undesirable outputs and strong disposability for the desirable outputs and inputs, a hyperbolic graph measure of technical efficiency is defined for producer $k$, and the following linear programming problem can be constructed to obtain the solution:

$$
\begin{aligned}
& H_{0}^{W}\left(y^{k}, b^{k}, x^{k}\right)=\min \Omega \\
& \text { s.to } \\
& Z^{T} Y \geq y^{k} \\
& Z^{T} B=\Omega b^{k} \\
& Z^{T} N \leq \Omega x^{k} \\
& Z^{T} \in R_{+}^{K} .
\end{aligned}
$$

Finally, the environmental efficiency index can be obtained from the ratio of these two efficiency scores as:

$H=\frac{\sqrt{\Gamma}}{\sqrt{\Omega}}$.

Under Fare et al.'s theory (1989a,b), many micro- and macro-level studies have been done to analyze the measure of environmental efficiency index. The use of macro data in studies that employ production-frontier techniques has been applied by Zaim and Taskin (2000a,b), who measure the environmental efficiency indices for OECD countries. 
This study measures environmental efficiency using country-level macro data for 111 countries for the 1980-2009 period, with real GDP of each country as the good output, aggregate capital and labor as inputs and $\mathrm{CO}_{2}$ emissions considered as the undesirable output, which is costly to freely dispose.

To calculate the environmental efficiency indices for each country, two linear programming problems (given in Section 2.1) are solved for each year between 1980 and 2009 using the General Algebraic Modeling System (GAMS) computer program. The ratio of two efficiency numbers computed from two linear programming problems under the technology that satisfies strong and weak disposability of undesirable goods gives each country's environmental efficiency index. ${ }^{18}$

\section{References}

Ambec, S., Barla, P., 2006. Can environmental regulations be good for business? An assessment of the Porter hypothesis. Energy Stud. Rev. 14 (2), 1.

Ambec, S., Cohen, M.A., Elgie, S., Lanoie, P., 2013. The Porter hypothesis at 20: can environmental regulation enhance innovation and competitiveness? Rev. Environ. Econ. Policy 7 (1), 2-22.

Anderson, J.E., 1979. A theoretical foundation for the gravity equation. Am. Econ. Rev. 69 (1), 106-116.

Anderson, J.E., 2011. The gravity model. Annu. Rev. Econ. 3 (1), 133-160.

Anderson, J., van Wincoop, E., 2003. Gravity with gravitas: a solution to the border puzzle. Am. Econ. Rev. 93 (1), 170-192.

Anderson, J., van Wincoop, E., 2004. Trade costs. J. Econ. Lit. 42 (3), 691-751.

Baines, T., Brown, S., Benedettini, O., Ball, P., 2012. Examining green production and its role within the competitive strategy of manufacturers. J. Ind. Eng. Manag. 5 (1), 53-87.

Baldwin, R., Taglioni, D., 2006. Gravity for dummies and dummies for gravity equations (no. w12516). Natl. Bur. Econ. Res.

Bergstrand, J.H., 1985. The gravity equation in international trade: some microeconomic foundations and empirical evidence. Rev. Econ. Stat. 474-481.

Bergstrand, $J \cdot H ., 1989$. The generalized gravity equation, monopolistic competition, and the factor-proportions theory in international trade. Rev. Econ. Stat. 71 (1), 143-153.

Bergstrand, J., Egger, P., 2011. Gravity equations and economic frictions in the world economy. Palgrave Handbook of International Trade, pp. 532-570.

Busse, M., 2004. Trade, environmental regulations and the WTO-new empirical evidence. J. World Trade 38 (2), 285-306

Cole, M.A., Elliott, R.J., 2003. Do environmental regulations influence trade patterns? Testing old and new trade theories. World Econ. 26 (8), 1163-1186.

Copeland, B.R., Taylor, M.S., 2004. Trade, growth, and the environment. J. Econ. Lit. 42 (1), 7-71.

De Santis, R., 2012. Impact of environmental regulations on trade in the main EU countries: conflict or synergy? World Econ. 35 (7), 799-815.

Deardorff, A., 1998. Determinants of bilateral trade: does gravity work in a neoclassical world? The Regionalization of the World Economy. University of Chicago Press, pp. 7-32.

Eaton, J., Kortum, S., 2002. Technology, geography, and trade. Econometrica 70 (5), 1741-1779.

Ederington, J., Minier, J., 2003. Is environmental policy a secondary trade barrier? An empirical analysis. Can. J. Econ. (Rev. Can. Econ.) 36 (1), 137-154.

Ederington, J., Levinson, A., Minier, J., 2005. Footloose and pollution-free. Rev. Econ. Stat. 87 (1), 92-99.
Environmental Protection Agency, 2012. Climate Change Indicators (Washington DC).

Esty, D.C., 2001. Bridging the trade-environment divide. J. Econ. Perspect. 15 (3), $113-130$

Fare, R., Grosskopf, S., Lovell, C.K., Pasurka, C., 1989a. Multilateral productivity comparisons when some outputs are undesirable: a nonparametric approach. Rev. Econ. Stat. 71 (1), 90-98.

Fare, R., Grosskopfand, S., Pasurka, C., 1989b. The effect of environmental regulations on the efficiency of electric utilities: 1969 versus 1975. Appl. Econ. 21 (2), 225-235.

Feenstra, R.C., 2004. Advanced International Trade: Theory and Evidence. Princeton University Press.

Frankel, J.A., Romer, D., 1999. Does trade cause growth? Am. Econ. Rev. 89, 379-399.

Grether, J.M., De Melo, J., 2003. Globalization and dirty industries: do pollution havens matter? (no. w9776). Natl. Bur. Econ. Res.

Harris, M.N., Konya, L., Matyas, L., 2002. Modelling the impact of environmental regulations on bilateral trade flows: OECD, 1990-1996. World Econ. 25 (3), 387-405.

Haveman, J., Hummels, D., 2004. Alternative hypotheses and the volume of trade: the gravity equation and the extent of specialization. Can. J. Econ. (Rev. Can. Econ.) 37 (1), 199-218.

Head, K., Mayer, T., 2013. Gravity equations: workhorse, toolkit, and cookbook. CEPR Discussion Papers 9322, C.E.P.R. Discussion Papers.

Helpman, E., Melitz, M., Rubinstein, Y., 2008. Estimating trade flows: trading partners and trading volumes. Q J. Econ. 123 (2), 441-487.

Jug, J., Mirza, D., 2005. Environmental regulations in gravity equations: evidence from Europe. World Econ. 28 (11), 1591-1615.

Levinson, A., Taylor, M.S., 2008. Unmasking the pollution haven effect*. Int. Econ. Rev. 49 (1), 223-254.

Mayer, T., Zignago, S., 2011. Notes on CEPII's distances measures: the GeoDist database. CEPII Working Paper 2011-25. Centre d'Etudes Prospectives et d'Informations Internationales, Paris.

Porter, M.E., Van der Linde, C., 1995. Toward a new conception of the environment-competitiveness relationship. J. Econ. Perspect. 9 (4), 97-118.

Shephard, R.W., 1970. Theory of Cost and Production Functions (No. 4). In: Gale, D., Kuhn, H.W. (Eds.), Princeton University Press, Princeton.

Silva, J.S., Tenreyro, S., 2006. The log of gravity. Rev. Econ. Stat. 88 (4), 641-658.

Song, M., An, Q., Zhang, W., Wang, Z., Wu, J., 2012. Environmental efficiency evaluation based on data envelopment analysis: a review. Renew. Sust. Energ. Rev. 16 (7), 4465-4469.

Tinbergen, J., 1962. An analysis of world trade flows. Shaping the World EconomyTwentieth Century Fund, New York.

Tobey, J.A., 1990. The effects of domestic environmental policies on patterns of world trade: an empirical test. Kyklos 43 (2), 191-209.

Van Beers, C., Van Den Bergh, J.C., 1997. An empirical multi-country analysis of the impact of environmental regulations on foreign trade flows. Kyklos 50 (1), 29-46.

Van Beers, C., Van Den Bergh, J.C., 2000. The impact of environmental policy on foreign trade: Tobey revisited with a bilateral flow model (no. 00-069/3). Tinbergen Institute Discussion Paper.

Wagner, M., 2003. The Porter Hypothesis Revisited: A Literature Review of Theoretical Models and Empirical Tests. Center for Sustainable Management, Lüneburg.

$\mathrm{Xu}, \mathrm{X}$., 2000. International trade and environmental regulation: time series evidence and cross section test. Environ. Resour. Econ. 17 (3), 233-257.

Yörük, B.K., Zaim, O., 2006. The Kuznets curve and the effect of international regulations on environmental efficiency. Econ. Bull. 17 (1), 1-7.

Yörük, B.K., Zaim, O., 2008. International regulations and environmental performance. Appl. Econ. 40 (7), 807-822.

Zaim, O., Taskin, F., 2000a. A Kuznets curve in environmental efficiency: an application on OECD countries. Environ. Resour. Econ. 17 (1), 21-36.

Zaim, O., Taskin, F., 2000b. Environmental efficiency in carbon dioxide emissions in the OECD: a non-parametric approach. J. Environ. Manag. 58 (2), 95-107.
18 A total of 6660 linear programming problems are solved to compute the environmental efficiency indices. 